\title{
VULNERABILITY ASSESMENT UNTUK MENINGKATKAN KUALITAS KEMANAN WEB
}

\author{
Mira Orisa ${ }^{1}$, Michael Ardita ${ }^{2}$ \\ ${ }^{1}$ Teknik Infomatika, Institut Teknologi Nasional Malang \\ ${ }^{2}$ Teknik Elektro, Institut Teknologi Nasional Malang \\ mir4orisa@gmail.com
}

\begin{abstract}
ABSTRAK
Aplikasi web sangat rentan terhadap serangan seperti sql injection, denial of service, dan berbagai macam bentuk malware lainnya. Kerentanan terjadi karena Banyak aplikasi web dirancang dari awal tanpa memperhitungkan masalah keamanan. Biasanya, aplikasi dirancang oleh orang yang tidak berpengalaman dalam bidang keamanan web. Sehingga memungkinkan banyak celah keamanan dalam website mereka. Metode vulnerability assessment ini adalah cara terbaik saat ini untuk membantu pihak-pihak tertentu dalam menjaga keamanan aplikasi web mereka. Dengan melakukan vulneribility assessment dapat mengidentifikasi macammacam celah yang memungkinkan masuknya serangan. Metode ini dapat membantu pihak-pihak tertentu untuk mengambil tindakan pencegahan terhadap serangan atau suatu kerusakan akibat kejahatan dunia maya. Network mapping atau dikenal dengan Nmap dapat membantu para master web untuk melakukan vulnerability assessment. Pada penelitian ini menggunakan OS kali Linux untuk menjalankan Nmap. Host target yang di uji mendukung metode POST, OPTIONS, GET, HEAD. Hasil pengujian VA dengan nmap juga menunjukkan bahwa target tersebut terdeteksi sebagai HTTP open proxy. Kemudian target yabg diuji tidak terdeteksi cross site scripting. Dan host target juga tidak terdeteksi sql injection.
\end{abstract}

Keyword : assessment,keamanan,vulnerability,web, Nmap.

\section{PENDAHULUAN}

Perkembangan teknologi internet dan sistem informasi saat ini telah meningkatkan jumlah pengguna aplikasi web. Setiap kali seseorang terkoneksi dengan internet maka saat itu juga mereka terkoneksi pada sebuah website. Banyak sekali dijumpai kerentanan pada aplikasi web. Kerentanan atau biasa disebut vulneribily mengundang para attacker untuk melakukan serangan dengan tujuan illegal. Serangan yang diluncurkan biasanya menyerang bagian syntax dan semantic dari aplikasi web. Berbagai macam cara dilakukan oleh attacker seperti menggunakan media sosial atau panggilan telepon untuk menipu orang agar mendapatkan akses ke informasi sensitive seseorang.

Untuk Mengantisifasi serangan tersebut para pengembang web harus melakukan vulnerability assessment. Vulnerability assessment dapat mendefinisikan, mengidentifikasi, mengelompokkan dan memprioritaskan kerentanan dalam sistem web. Vulnerability pada aplikasi web dapat di deteksi menggunakan tool atau software tertentu. Menurut referensi [1], scanning pada aplikasi web bertindak sebagai pelengkap dan menguji kinerja serangan pada target. Contohnya Payment Card Industry Data Security Standart (PCI DSS) versi 2.0, sekarang mewajibkan semua pedagang yang menerima kartu pembayaran untuk lulus pemindaian untuk vulnerability pada aplikasi web.

Ashikali Hasan dan Divyakant Meva pada tahun 2018 melakukan penelitian untuk menghilangkan berbagai jenis ancaman keamanan pada aplikasi web dengan metode vulnerability assessment dan penetration testing. Sehingga ancaman seperti $S Q L$ injection, cross site scripting, local file inclusion and remote file inclusion dapat di hilangkan menggunakan sebuah tool yaitu proses VAPT [2]. Dalam Penelitian Hilal Afrih Juhad dan kawan-kawan, pengguna sebuah website harus memiliki kesadaran akan pentingnnya perlindungan terhadap informasi yang ada dalam website seperti menentukan hak akses, mengidentifikasi penggunjung website. Karena jika tidak maka seorang attacker akan mengambil keuntungan dari vulnerability yang ada. Ari marta tania dan kawankawan pada tahun 2018 menggunakan sebuah tool bernama CVSS (Common Vulnerability Scoring System) versi 2 untuk mengkomunikasikan karakteristik dan dampak yang ditimbulkan vulnerability [3].

Pengetahuan tentang aspek keamanan sangat penting diketahui oleh seorang master web. Dengan metode vulnerability assessment dapat membantu mendeteksi kerentanan dalam sebuah aplikasi web. Hasil dari assessment tersebut menjadi pertimbangan bagi master web untuk mengambil tindakan pencegahan serta mengetahui kinerja serangan saat melakukan serangan.

\section{TINJAUAN PUSTAKA}

\subsection{Penelitian Terkait}

Ari Marta Tania dan kawan-kawan mendeteksi beberapa sserangan seperti brute force attack dan denial of service, sniffing dengan menggunakan beberapa tool diantaranya Wpscan, exploit, metasploit-Framework dan THC-Hydra, slowlori,

Copyright (c) 2021 Jurnal Mnemonic 
webscarab [4]. Imam Riadi dan kawan-kawan menggunakan tool owasp untuk menganalisis keamanan website open journal system (OJS) versi 2.4.7 Hasil dari assessment menyatakan bahwa OJS versi 2.4.7 memiliki banyak vulnerability [5]. Selain itu tool yang dapat melakukan penetrasi diantaranya W3af, Havij, Fimap, Metasploit, Kali linux, Acunetix, dan Nexpose [2]. Pada penelitian yang dilakukan oleh Said F. Aboelfotoh dan Noha A. Hikal menggunakan tool nmap sebagai tool untuk assessment jaringan [6].

\subsection{B. Vulnerability Assessment}

Vulnerability assessment digunakan untuk melakukan pengujian pada point-point yang berpotensial masuknya serangan. Selain itu juga mengidentifikasi masa berlakunya versi sebuah software, mengidentifikasi port-port yang terbuka, dan dapat juga mengidentifikasi aplikasi apa saja yang sedang berjalan. Vulnerability assessment digunakan untuk mendeteksi kelemahan dalam jaringan [6].

MTTR (mean time to remediate) merupakan total rata-rata di seluruh aplikasi web dan kerentanan infrastruktur, ditunjukkan pada Gambar 1 [7]

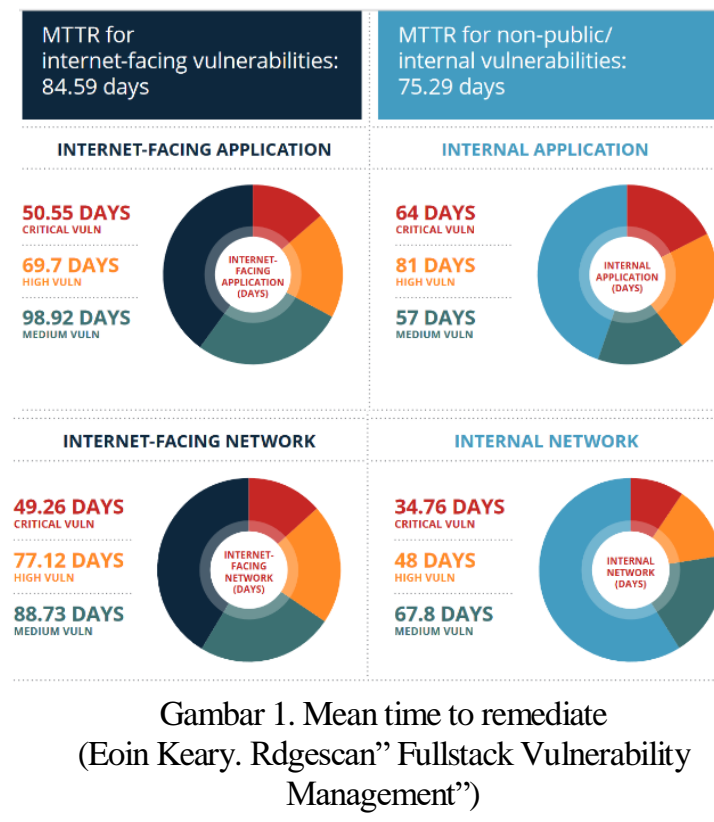

Besar risiko kritis Internet dalam menghadapi kerentanan aplikasi web hampir sama dengan besar risiko kritis Internet dalam menghadapi kerentanan jaringan yaitu masing-masing 50,55 hari dan 49,26 hari.

\subsection{Network Mapper}

Network Mapper atau dikenal dengan nmap. Namap lebih optimal bekerja di system operasi Linux dari pada windows. Nmap merupakan tool yang biasa digunakan untuk melakukan audit keamanan jaringan dan melakukan eksplorasi jaringan. Namap merupakan tool yang bersifat open source. Aplikasi bawaan dari nmap seperti: [8]

1. Zenmap yang merupakan nmap versi GUI

2. Ndiff merupakan tool yang diperuntukkan untuk membandingkan hasil scanning

3. Nping merupakan tool untuk analisis paket data

4. Ncrak merupakan tool yang digunakan untuk melakukan brute-force

5. Ncat merupakan tool untuk read dan write data pada jaringan

6. NSE merupakan fitur dimana anda dapat menulis script sendiri untuk melakukan scanning.

Namap dapat ampuh menemukan vulnerability dalam sebuah jaringan dan selain itu nmap juga merupakan tool yang bisa melakukan pengelolaan server. Namap bisa melakukan scanning jaringan dengan teknik [8]:

1. Port scanning

Teknik port scanning ini bertujuan memindai port host tetentu apakah sedang terbuka. Jika port suatu aplikasi dalam jaringan computer terbuka, maka siapaun akan bisa masuk dan dapat mengakses aplikasi tersebut. Selain dapat melihat status terbuka atau tertutup sebuah port dalam jaringan, Nmap juga bisa melihat status lainnya seperti: filtered, unfiltered, open/filtered, dan closed/filtered.

2. Ping scanning

Teknik ping scanning berfungsi untuk mengetahui apakah host sedang aktif atau tidak di jaringan. Teknik ini diantaranya [8]:

3. Ping scanning TCP SYN

Ketika ada firewall yang memblokir permintaan pin scan yang ber flag -sp untuk meminta respons dari host yang ada didalam jaringan, sehingga Nmap tidak bisa melihat host aktif maka digunakan pin scan TCP SYN.

4. Ping scan TCP ACK

Ping scan TCP ACK digunakan jika teknik ping scan TCP SYN diblokir oleh firewall.

5. Ping scan UDP

Teknik ini bisa digunakan jika dua teknik diatas diblokir oleh firewall.ini merupakan teknik alternative.

6. Ping scan ICMP

Penggunaan teknik ini saat pada hak akses root. Teknik ping scan ICMP juga masih bisa di blokir oleh firewall.

7. Ping scan IP

Pada teknik ini Nmap membutuhkan hak akses root. Adapun protocol IP yang dimaksud adalah IGMP, IP-in-IP dan ICMP. Tabel 2 menunjukkan daftar nomer pada protocol pin scan IP 
Tabel 2. Daftar nomer protocol ping scan IP

\begin{tabular}{|c|c|}
\hline Nomor & Protokol \\
\hline 1 & ICMP \\
\hline 17 & UDP \\
\hline 6 & TCP \\
\hline 2 & IGMP \\
\hline 4 & IP-in-IP \\
\hline 132 & SCTP \\
\hline
\end{tabular}

(sumber: Abdullah,2016)

Adapun celah vulnerability atau kerentanan web yang sering dimanfaatkan oleh para hacker untuk mengencarkan serangan, diantaranya [9]:

1. HTTP Header

HTTP header bisa menjadi celah kerentanan karena dia dikirim oleh client yang tidak sepenuhnya bisa dipercaya.

2. HTML Injection

Injeksi HTML bisa menjadi jalan masuknya serangan dari hacker

3. Pengunaan metode GET

Ada dua metode pengiriman yaitu POST dan GET. Jika master web menggunkan metode GET maka data yang dikirim akan terlihat di URL. Para hacker tentu akan memanfaatkan celah ini dengan merubah halaman atau membuat script tertentu untuk keuntungan dirinya.

4. Cookie

Hacker biasanya memanfaatkan cookie untuk masuk kehalaman target tanpa melalui login terlebih dahulu. Creaker bisa mencuri username dan password pengguna resmi.

5. Shell injection

Para hacker menjalankan perintah system operasi pada web. seperti perintah "ping \& dir c."

6. Hacking perintah include

Perintah include dalam pemprograman php terkadang bisa menjadi celah masuknya serangan hacker. Hacker bisa saja membuka file.inc

Sebagian orang akan selalu mengaitkan antara penetration testing dengan vulnerability assessment. Adahal ada perbedaannya antara penetration testing dan vulnerability assessment, seperti ditunjukkan pada Tabel 1[10].

Tabel 1. Perbedaan antara penetration testing dan vulnerability assessment

\begin{tabular}{|l|l|}
\hline Penetration testing & $\begin{array}{l}\text { Vulnerability } \\
\text { assessment }\end{array}$ \\
\hline $\begin{array}{l}\text { Identifikasi beberapa } \\
\text { celah keamanan }\end{array}$ & $\begin{array}{l}\text { Identifikasi semua } \\
\text { celah keamanan }\end{array}$ \\
\hline Pendekatan risiko IT & $\begin{array}{l}\text { Pendekatan bisnis dan } \\
\text { risiko IT }\end{array}$ \\
\hline $\begin{array}{l}\text { Pembuktian secara } \\
\text { teknis }\end{array}$ & $\begin{array}{l}\text { Pembuktian secara } \\
\text { teori }\end{array}$ \\
\hline
\end{tabular}

(sumber: Girindro pringgo Digdo,2017)

\section{METODELOGI}

Metode penelitian terdiri dari beberapa tahap yaitu mengidentifikasi asset, menilai asset, menidentifikasi kerentannan, melaporkannya. Seperti terlihat pada Gambar 2.

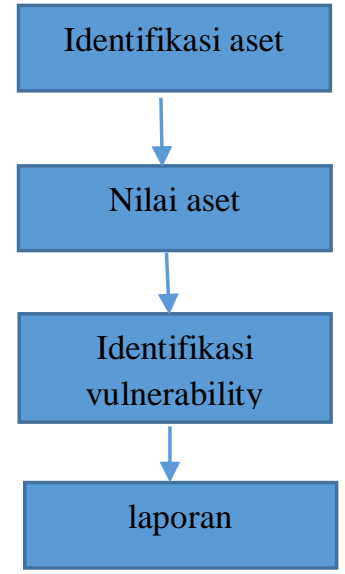

Gambar 2. Metode vulnerability assessment [4]

Vulnerablity assessment dilakukan dengan menggunakan Nmap Scripting Engine (NSE). Seperti yang ditunjukkan pada Gambar 2, dimana akan dilakukan pengecekkan terhadap malware/web phising dan sql injection. Kategori di Nmap Scripting Engine (NSE) ini memiliki fungsi nya masing-masing. Nmap Scripting Engine (NSE) dapat dipergunakan oleh master web sebagai tool untuk vulnerability assessment.

\section{HASIL DAN PEMBAHASAN}

Hasil pengujian web server scanning antara lain: mendeteksi metode pada protocol HTTP dengan perintah \$nmap -p80,443 -script httpmethods <target>. Pada host target tersebut mendukung metode POST, OPTIONS, GET, HEAD.

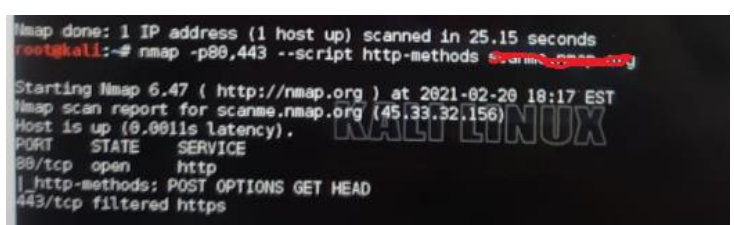

Gambar 3. Deteksi metode protocol HTTP

Hasil untuk kategori script NSE nmap \$nmap p8080 -script http-open-proxy <target>, menunjukkan bahwa target tersebut terdeteksi sebagai HTTP open proxy.

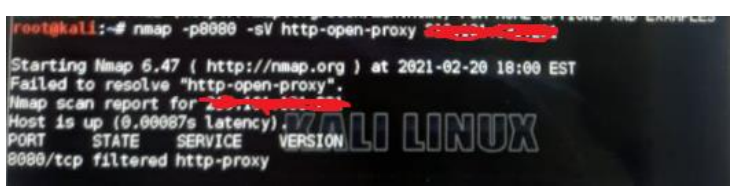

Gambar 4. Scanning open proxy HTTP 
Hasil untuk kategori script NSE nmap \$ nmap -p 80 -script dns-brute.nse.nse <target>, untuk menemukan dns yang valid.

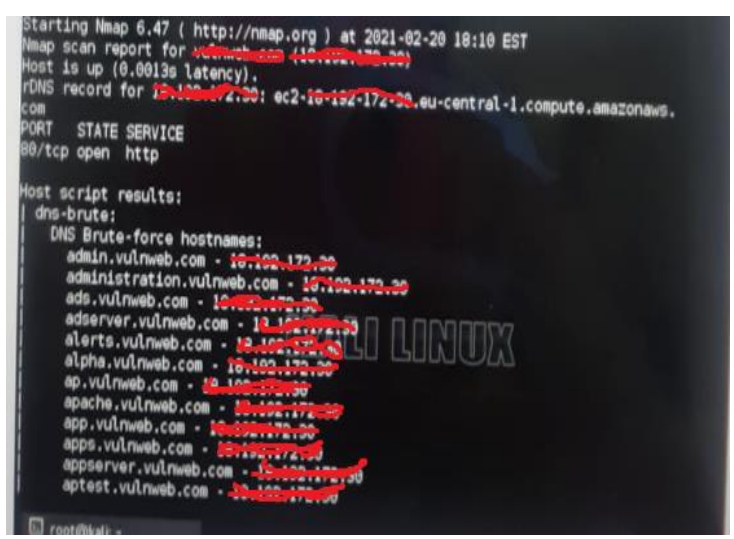

Gambar 5. Dns Brute

Hasil untuk kategori script NSE nmap \$ nmap -script http-unsafe-output-escaping -p80 <target>. Saat dilakukan scanning tersebut pada host target tidak terdeteksi cross site scripting.

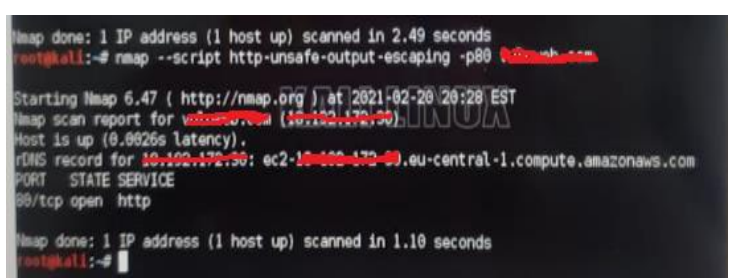

Gambar 6. Dmendeteksi cross site scripting

Hasil untuk kategori script NSE nmap \$ nmap -script http-aql-injection $-\mathrm{p} 80<$ target>. Saat dilakukan scanning tersebut pada host target tidak terdeteksi sql injection.

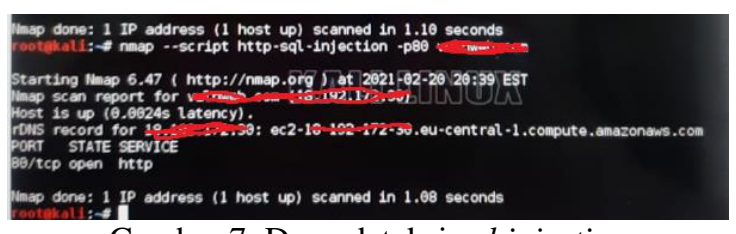

Gambar 7. Dmendeteksi sql injection

\section{SIMPULAN}

Network mapping atau Nmap merupakan tool yang mampu melalukan vulnerability assessment untuk melakukan pengecekan masalah malware/web phising, dapat melakukan pengecekan terhadap serangan denial of service, dapat menemukan vulnerability xss pada file php, dan dapat menemukan vulnerability terhadap serangan sql-injection. Pada penelitian ini, host target yang di uji mendukung metode POST, OPTIONS, GET, $H E A D$. Menunjukkan bahwa target tersebut terdeteksi sebagai HTTP open proxy. Tidak terdeteksi cross site scripting. Pada host target tidak terdeteksi sql injection.

\section{DAFTAR PUSTAKA}

[1] Shema.M.2011.Web Application Security for Dummies.A john wiley and Sons, Ltd, Publication

[2] Hasan.A, \$ D. Meva. 2018. Web application Safety Penetration Testing.Special Issue based on proceeding of $4^{\text {th }}$ International Conference on Cyber Security (ICCS).

[3] Juhad. H. A, R. Isnanto, E. D. 2016.Widianto. Analisis Keamanan pada Aplikasi Her-registrasi Online Mahasiswa Universitas Diponegoro.Jurnal Teknologi dan Sistem Komputer. 4(3). 2016. 479484. DOI:10.1470/jtsiskom.4.3.2016.479-484

[4] Tania. A. M., D. Setiyadi, \& F. N. Khasanah. 2018. Keamanan Website Menggunakan Vulnerability Assessment. Informatics for Educator and Professionals. vol.2.no.2. 2018. E_ISSN: 25483412

[5] Riadi. I, A. Yudhana, \& Yunanri. 2018. Analisis Keamanan Website Open Journal System Menggunakan Metode Vulnerability Assessment. Jurnal Teknologi Informasi dan Ilmu Komputer (JTIIK). vol.7.no.4. 2020. 853-860. E-ISSN: 25286579

[6] Aboelfotoh. S. F, \& N. A. Hikal. A. 2020. Review of Cyber-Security Measuring and Assessment Methods for Modern Enterprise. International Journal on Informatics Visualization. vol.3.no.2. 2019. E-ISSN: 2549-9904. ISSN: 2549-9610

[7] Keary. E. 2020. Rdgescan," Fullstack Vulnerability Management".

[8] Abdullah.2016. Kung Fu Hacking dengan Nmap. Penerbit: ANDI. Yogyakarta.

[9] S'to. 2009. Web Hacking: Scenario \& Demo.Penerbit: jasakom. Edisi revisi dari buku best seller SIH Recoded.

[10] Pringgo. D. G. 2017. panduan audit keamanan computer bagi pemula. penerbit PT.elex media komputindo. 